\title{
Article
}

\section{Sex Differentiation and Early Gonadogenesis in Sebastes inermis Cuvier}

\author{
Hee Jung Choi ${ }^{1}$, Sung-Young $\mathrm{Oh}^{1}$, Jung-Goo Myoung ${ }^{1}$, Jong-Man Kim ${ }^{2}$, \\ Jun Wook Hur ${ }^{3}$, Min-Ouk Park ${ }^{4}$, and In-Seok Park ${ }^{4 *}$ \\ ${ }^{1}$ Marine Living Resources Research Department, KORDI \\ Ansan P.O. Box 29, Seoul 425-600, Korea \\ ${ }^{2}$ Gyeongbuk Institute for Marine Bio-Industry \\ Uljin 767-813, Korea \\ ${ }^{3}$ Center for Integrated Water Management Research, KIWE \\ Daejon 305-730, Korea \\ ${ }^{4}$ Division of Marine Environment and Bioscience \\ College of Ocean Science and Technology, Korea Maritime University \\ Busan 606-791, Korea
}

\begin{abstract}
Early gonadal development and sexual differentiation of dark-banded rockfish (Sebastes inermis Cuvier) were followed from parturition to 400 days post parturition (dpp). During this period, average total length (TL) increased from 0.57 to $13.18 \mathrm{~cm}$. Primordial germ cells (PGCs) were first detected at $0.68 \mathrm{~cm}$ TL (10 dpp). When fish reached $1.52 \mathrm{~cm}$ TL (50 dpp), initial stages of ovarian differentiation were identified by the presence of PGCs containing condensed chromatin and their transformation into meiotic oocytes. At $10.23 \mathrm{~cm}$ TL (300 dpp), the ovaries gradually developed into oocytes in the primary yolk stages. Ovary growth was rapid after sex differentiation, but testis tissue continued to multiply without growing until fish reached $6.97 \mathrm{~cm}$ TL $(200 \mathrm{dpp})$, after which the production of spermatocytes, spermatogonia, and cyst cells was apparent. Histological analysis of gonadal structure suggested a gonochoristic sexual development pathway. Our analysis of the sex ratio at $400 \mathrm{dpp}$ showed a significantly higher proportion of males.
\end{abstract}

Key words : dark-banded rockfish, gonadogenesis, sex differentiation

\section{Introduction}

The dark-banded rockfish Sebastes inermis Cuvier (Scorpaenidae) is ovoviviparous (Lee and Kim 1992; Choi et al. 2002). Its distributional range extends from Hokkaido, Japan, through the East Sea to Jeju Island, Korea; this fish is generally restricted to waters of rocky seashores (Kim et al. 1993; Kim and Han 1993; Choi et al. 2002). An important food fish in Korea, dark-banded rockfish is a viable candidate for commercial mariculture, both in terms of market potential and the ability of the species to tolerate a wide range of environmental conditions (Ko et al. 1998; Kim et al. 2001).

\footnotetext{
*Corresponding author. E-mail : ispark@hhu.ac.kr
}

Many teleosts are gonochorists, in which individuals develop separately as males and females and remain so throughout their life history (Devlin and Nagahama 2002). There is a range of early gonadal development pathways among gonochoristic species. Yamamoto(1969) summarized historical data and identified two major types. In differentiated gonochorism (also termed primary gonochorism; Atz 1964), early gonad development proceeds from an undifferentiated gonad directly to ovary or testis. The alternative mode of gonadal development is found in undifferentiated gonochorism, in which all individuals initially develop ovarian tissue, but in approximately half of the fish, this ovarian tissue degenerates and the gonad is invaded by additional somatic cells (Takahashi 1977; Takahashi and Shimizu 1983). 
To date, there is little information on life-history parameters of dark-banded rockfish. Given their valuable status as food fish, and their mariculture potential, there is an urgent need for comparative demographic and lifehistory analyses of this species, especially as populations are declining, primarily as a result of increasing pollution in coastal waters (Kim et al. 2001).

In teleosts, the pattern of sex differentiation may be divided into synchronous hermaphroditism (protandrous and protogynous), and gonochorism (undifferentiated and differentiated; Yamamoto, 1969). In the late 1930s and early 1940s, it was shown that gonadal sex of fish can be influenced by hormone administration (Hunter and Donaldson 1983; Yamazaki 1983; Piferrer 2001); this demonstration, coupled with the enormous expansion of fish culture in recent decades, provides an impetus for enhancement of secondary sexual characteristics associated with morphological, physiological, or etiological traits that may be advantageous in certain mariculture procedures (Hunter and Donaldson 1983; Yamazaki 1983; Piferrer 2001).

Hormonal sex reversal can be induced by treatment with exogenous sex steroids during the period of sex differentiation (Yamamoto 1969; Hunter and Donaldson 1983). Clearly, an adequate knowledge of early reproductive biology of dark-banded rockfish is essential in estimating the exact timeline for hormone treatment to reverse sex (Hunter and Donaldson 1983; Yamazaki 1983; Park et al. 1993); comprehensive information on early sexual differentiation is also of importance for an understanding of stock recruitment.

We analyzed dark-banded rockfish sex differentiation and early gonadogenesis to determine stages of gonadal sex differentiation while evaluating experimental conditions required to achieve sex reversal.

\section{Materials and methods}

Larval fish were reared in a concrete tank $(5 \times 5 \times 1.2$ $\mathrm{m})$. Water temperature and salinity were maintained at $14.0 \sim 15.5^{\circ} \mathrm{C}$ and $34 \pm 0.6$ ppt. Fish were fed rotifers (six times daily) from 2 to 15 days post parturition (dpp), rotifers (four times daily) and Artemia (twice daily) from 16 to $30 \mathrm{dpp}$, Artemia (four times daily) from 31 to 45 dpp, Artemia and commercial feed $(400 \mu \mathrm{m})$ from 46 to $75 \mathrm{dpp}$, and commercial feed from $76 \mathrm{dpp}$.

Larvae $(n=50)$ were sampled at 10 -day intervals from parturition to $100 \mathrm{dpp}$, at 20-day intervals from 120 to $200 \mathrm{dpp}$, and at 50-day intervals from 250 to $400 \mathrm{dpp}$.
Sampled fish were starved for 24 hours prior to each sampling to avoid possible confounding effects of gut fullness variability on body mass measurements (Grove et al. 1978).

Sampled fish were euthanized with an overdose of lidocaine- $\mathrm{HCl} / \mathrm{NaHCO}_{3}$ and fixed in chilled formalin prior to measurement. Total length (TL, cm) and body weight $(\mathrm{g})$ of ten specimens were measured to the nearest $0.01 \mathrm{~cm}$ and $0.01 \mathrm{~g}$ on each sampling occasion. For histological analysis, samples were fixed in $10 \%$ neutral formalin, after which they were placed in Bouin's fixative for 24 hours and in formic acid and sodium citrate for decalcification. Subsequently, specimens (excluding head and caudal region) were processed for histological analysis by routine dehydration in graded alcohol, followed by paraffin wax embedding procedures. Crosssections 4-6 $\mu \mathrm{m}$ thick were stained with Mayer's hematoxylin and eosin phloxine B solution, examined, and microphotographed (Park et al. 1998, 2004).

To ascertain sex ratio at 400 and $800 \mathrm{dpp}$, sections of gonad structure $(n=90)$ were analyzed by the histological procedures outlined above. Sex ratio was assessed by a chisquared test, and differences were considered significant at $P<0.05$; calculations were executed with Excel software.

\section{Results and discussion}

At $10 \mathrm{dpp}(0.68 \mathrm{~cm}$ TL), gonads of dark-banded rockfish were apparent on both sides of the mesonephric duct, adjacent to the genital ridge in the abdominal cavity (Fig. 1a). The presumptive gonad region is termed the germinal ridge (Balinsky 1975), which forms as a longitudinal thickening of mesoderm that protrudes into the coelomic cavity ventrally to the developing kidney and laterally to the dorsal mesentery (Devlin and Nagahama 2002). In Ditrema temmincki (Lee and Lee 1996) and Sebastes schlegeli (Lee et al. 1996), primordial germ cells (PGCs) occur in the dorsal mesentery along this route (mesenchymal tissue between the alimentary tract and the dorsal body wall).

PGCs were large and oval, approximately 5-6 $\mu \mathrm{m}$ in diameter, and enclosed by loose connective tissue. Their cytoplasm was weakly stained by hematoxylin, and the cells contained round nuclei 1-2 $\mu \mathrm{m}$ in diameter (Fig. 1b). At $50 \mathrm{dpp}$ (1.52 cm TL), some PGCs contained condensed chromatin, while oocytes 3-6 $\mu \mathrm{m}$ in diameter were observed in meiotic prophase. The PGCs and oocytes were enclosed by somatic cells (Fig. 1c). Devlin and Nagahama (2002) noted that the structure of fish gonads is similar to 

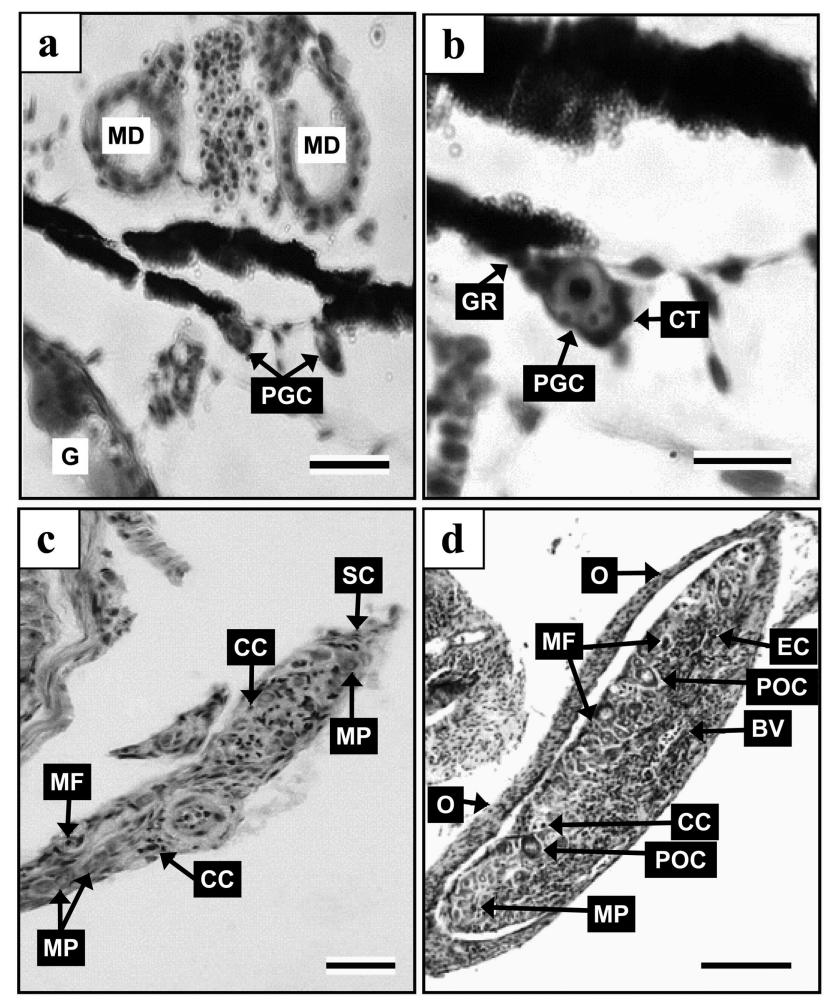

Fig. 1. Early gonadogenesis of dark-banded rockfish, Sebastes inermis (H-E staining). (a) Transverse section of gonad at 10 days post parturition (dpp). The gonad consists of a genital ridge adjacent to the mesonephric duct; the gonad contains primordial germ cells (PGCs; scale bar, 20 $\mu \mathrm{m})$. (b) PGC (scale bar, $10 \mu \mathrm{m}$ ). (c) Transverse section of the early differentiated ovary at 50 dpp. Note PGCs developing into oocytes by meiosis (scale bar, $20 \mu \mathrm{m}$ ). (d) Transverse section of the early differentiated ovary at 100 dpp. Note the presence of the primary oocyte in the chromatin-nucleolus stage. Meiotic figures are common (scale bar, $100 \mu \mathrm{m}$ ). BV: blood vessel, CC: condensed chromatin, CT: connective tissue, EC: endo-ovarian canal, G: gut, GR: genital ridge, MD: mesonephric duct, MF: meiotic figure, MP: meiotic prophase, O: ovolemma, PGC: primordial germ cell, POC: primary oocyte in the chromatin-nucleolus stage, SC: somatic cell, WSB: wall of swim bladder.

that of other vertebrates, with germ cells and associated supporting somatic cells intermixed within both ovary and testis tissues; a clear distinction between germ and somatic cells can be made (particularly at later stages), with the former having the potential to mitotically divide and enter meiosis, while the latter differentiate into associated structural and endocrine cell types. In our specimens, this early differentiated ovary became apparent along the gut,
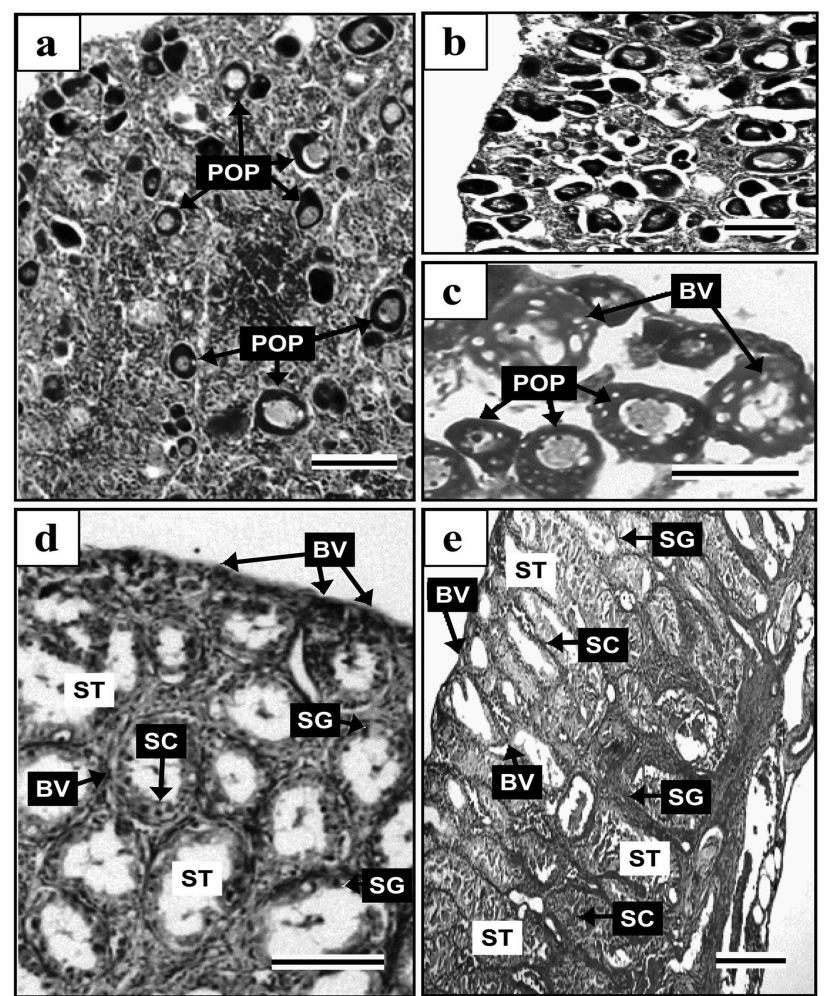

Fig. 2. Early gonadogenesis in dark-banded rockfish, Sebastes inermis (H-E staining). (a) Transverse section of an ovary at 200 days post parturition (dpp). Numerous primary oocytes can be seen in the chromatin-nucleolus and perinucleolus stages (scale bar $100 \mu \mathrm{m}$ ). (b) Transverse section of an ovary at $250 \mathrm{dpp}$. Note the yolk vesicle starting to appear in the cytoplasm of primary oocytes in the perinucleolus stage (scale bar, $100 \mu \mathrm{m}$ ). (c) Transverse section of an ovary at 300 dpp. Note the primary oocytes in a stage intermediate between the chromatin-nucleolus and yolk vesicle stages (scale bar, $100 \mu \mathrm{m})$. (d, e) Transverse section (d) and longitudinal section (e) of the early differentiated testis at 200 dpp. Note the cyst composed of spermatogonia and spermatocytes (scale bars, $100 \mu \mathrm{m}$ ). BV: blood vessel, EC: endo-ovarian canal, IC: interstitial cell, POC: primary oocyte in the chromatin-nucleolus stage, POP: primary oocyte in the perinucleolus stage, POY: primary oocyte in the yolk vesicle stage, SC: spermatocyte, SG: spermatogonia, ST: seminiferous tubule, TC: thecal cell, YV: yolk vesicle.

where it lay adjacent to the epithelial cells in the body cavity. In most cases, PGCs appear to migrate directly to gonad tissues. However, in sturgeon, PGCs can migrate to other organs such as the liver (Romanov and Altuf'yev 1992, 1993).

After $100 \mathrm{dpp}(3.78 \mathrm{~cm} \mathrm{TL}, 0.76 \mathrm{~g} \mathrm{BW})$, numerous oocytes were present in meiotic prophase. Oocytes were 
in the chromatin-nucleolus stage, with blood vessels and endo-ovarian canals beginning to fill the ovary (Fig. 1d). At $200 \mathrm{dpp}$ (6.97 cm TL, $6.60 \mathrm{~g} \mathrm{BW}$ ), the oocytes were in the peri-nucleolus stage and increased from 40 to $50 \mu \mathrm{m}$ diameter (Fig. 2a). Oocyte nucleoplasm was distinguishable from cytoplasm by the presence of a pallial layer consisting of intensely stained granules. At $250 \mathrm{dpp}$ (8.49 cm TL, $13.21 \mathrm{~g} \mathrm{BW}$ ), oocytes moved into the primary growth phase with basophilic oocytes at the yolk vesicle stage and, subsequently, at the yolk stage (indicated by the yolk globules surrounding the nucleus, Fig. 2b). Oocytes were enclosed by follicular cells, which were characterized by their irregular form and darkly stained cytoplasm (Fig. 2b). At 300 dpp (10.23 cm TL, 25.62 g BW), many oocytes were in a stage intermediate between the chromatin-nucleolus to yolk vesicle stages. The diameter of the oocytes ranged from 50 to $80 \mu \mathrm{m}$ (Fig. 2c).

At $200 \mathrm{dpp}(6.97 \mathrm{~cm} \mathrm{TL}, 6.60 \mathrm{~g} \mathrm{BW})$, spermatogonia were distinguishable from PGCs (Fig. 2d, e). The number of spermatogonia and spermatocytes increased; spermtogonia were enclosed by cysts and interstitial cells. Connective tissues were apparent around the spermatogonia, and blood vessels were scattered within the testis and testis epithelial cells. The testis was organized into a tubular structure consisting of seminiferous tubules and a long sperm duct. Testis somatic cells (surrounding PGCs) differentiated into seminiferous tubules, supporting connective tissue, and cells similar to Leydig and Sertoli cells found in mammals (Da Cruz-Huefling and Da CruzLandim 1984; Pudey and Callard 1984; Van Vuren and Soley 1990).

This period has been identified as "labile," because it is sensitive to hormonal treatment and generally appears to be the exact point of sexual differentiation. It lasts from 10 to 30 days post hatching ( $\mathrm{dph}$ ) in cyprinodontids, 10 to $40 \mathrm{dph}$ in cichlids, and 3 to $40 \mathrm{dph}$ in anabantids (Shelton and Jensen 1979; Pandian and Sheela 1995). In darkbanded rockfish, this period starts later than in other species examined. The starting point for females was 50 dpp, but was prolonged; in males, the starting point was $200 \mathrm{dpp}$, with rapid completion soon thereafter. These observations concur with an earlier report by Yamamoto (1969), who showed that differentiation of the ovary commences earlier than that of the testis in gonochoristic teleosts.

Once sex has been determined in mammalian reproductive systems, gonadal differentiation usually proceeds down a single developmental pathway to yield fully differentiated testes or ovaries (Hawkins 1994; Capel
Table 1. Sex ratio of dark-banded rockfish, Sebastes inermis, at 400 and 800 days post parturition. Proportions (as percentages) are given in parentheses

\begin{tabular}{ccc}
\hline \multirow{2}{*}{ Sex ratio $(\%)$} & \multicolumn{2}{c}{ Day post parturition } \\
\cline { 2 - 3 } & $\mathbf{4 0 0}$ & $\mathbf{8 0 0}$ \\
\hline Female & $34 / 90(37.8)$ & $36 / 90(40.0)$ \\
Male & $56 / 90\left(62.2^{\mathrm{a}}\right)$ & $54 / 90(60.0)$ \\
$x^{2}(\mathrm{df})$ & $5.378(1)$ & $3.600(1)$ \\
$P$ value & 0.020 & 0.058 \\
\hline
\end{tabular}

${ }^{a}$ Sex ratio significantly different from expected 1:1 $(P<0.05)$; $n=90$.

1998). In fish, there are many exceptions to these rules; development of the gonad may be influenced by fluctuations in intrinsic factors such as growth or behavior, or by extrinsic environmental factors such as temperature, endocrine hormones, pollution, or fishing pressure, all of which can selectively influence sex ratio (Devlin and Nagahama 2002). We found a higher proportion of males to females in dark-banded rockfish at 400 and $800 \mathrm{dpp}$ (Table 1). The sex ratio was significantly different from 1:1 at $400 \mathrm{dpp}$. However, in another rockfish, Sebastes oblongus, we found a higher proportion of females (1:0.52; Yoon et al. 2007).

Since gonadal development may be influenced by a variety of factors, further detailed studies of rockfish are required to describe specific life history and demographic parameters, such as age of first sexual maturation and spawning periodicity. Many fish have autosomal control of sexual development, and in these cases a 1:1 sex ratio is often observed. However, environmentally induced sex determination has been found in an increasing number of fish species (Baroiller et al. 1999). Among environmental factors, temperature is the most frequently studied. Rearing temperature influences sexual differentiation during the labile period of gonad development (Conover and Fleisher 1986).

Our study shows that the dark-banded rockfish has differentiated gonochoristic development (Fig. 3), and we provide novel and detailed baseline information about gonadogenesis in this species. What we learned will help establish a protocol for sex reversal, which may be useful for laboratory sex-control experiments and to support future aquaculture research.

\section{Acknowledgements}

We thank the staff of the Fishery Genetics and Breeding 


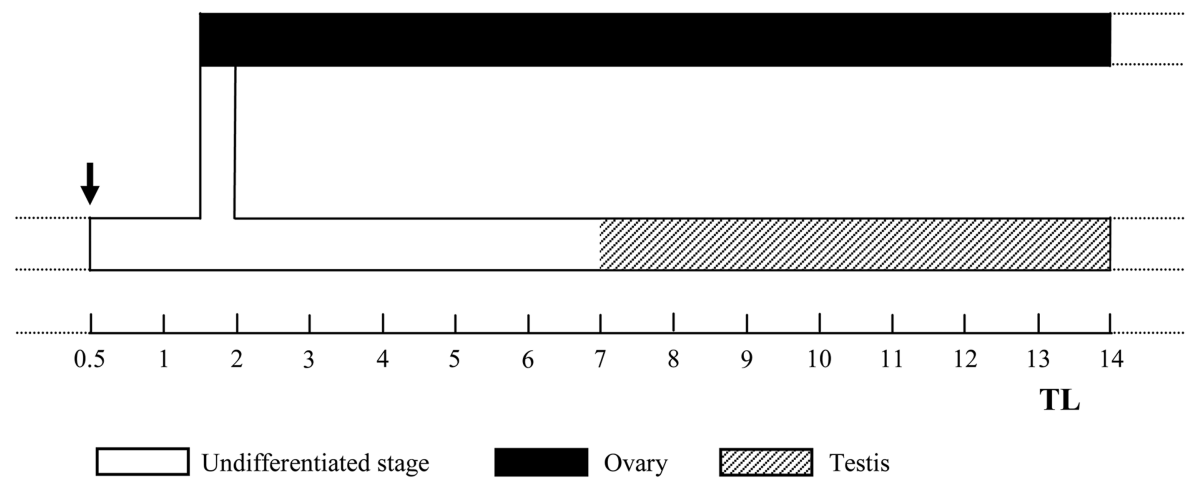

Fig. 3. Diagram of gonadal development and differentiation in the dark-banded rockfish Sebastes inermis in relation to body size. TL: total length. Arrow indicates the time of primordial germ cell appearance.

Science Lab, Division of Marine Environment and Bioscience, College of Ocean Science and Technology, Korea Maritime University, for excellent technical assistance. We also thank anonymous reviewers for comments that greatly improved this manuscript.

\section{References}

Atz, J.W. 1964. Intersexuality in fishes. P. 145-232. In: Intersexuality in Vertebrates Including Man, ed. by C.N. Armstrong and A.J. Marshall. Academic Press, London.

Balinsky, B.I. 1975. An introduction to Embryology. Saunders, Philadelphia. $648 \mathrm{p}$.

Baroiller, J.F., Y. Guiguen, and A. Fostier. 1999. Endocrine and environmental aspects of sex differentiation in fish. Cell Mol. Life Sci., 55, 910-931.

Capel, B. 1998. Sex in the 90s: SRY and the switch to the male pathway. Annu. Rev. Physiol., 60, 497-523.

Choi, Y., J.H. Kim, and J.Y. Park. 2002. Marine Fishes of Korea. Kyo-Hak Pubulishing Co., Ltd., Seoul. 645 p.

Conover, D.O. and M. Fleisher. 1986. The temperature-sensitive period of sex determination in Menidia menidia. Can. J. Aquat. Sci., 43, 514-520.

Da Cruz-Huefling, M. and C. Da Cruz-Landim. 1984. Ultrastructural and histochemical studies on the Leydig and Sertoli cell homologues in the testis of Triportheus elongatus (Sardinhao) and Mylossoma aureum (Pacu). Cytobios, 41, 161-174.

Devlin, R.H. and Y. Nagahama. 2002. Sex determination and sex differentiation in fish: an overview of genetic, physiological, and environmental influences. Aquaculture, 208, 191-364.

Grove, D.J., L. Lozoides, and J. Nott. 1978. Satiation amount, frequency of feeding and gastric emptying rate in Salmo gairdneri. J. Fish Biol., 12, 507-516.

Hawkins, J.R. 1994. Sex determination. Hum. Mol. Genet., 3, 1463-1467.

Hunter, G.A. and E.M. Donaldson. 1983. Hormonal sex control and its application to fish culture. p. 203-223. In:
Fish Physiology, Vol. IX, Part B, Behaviour and Fertility Control., Chap 5, ed. by W.S. Hoar, D.J. Randall, and E.M. Donaldson. Academic Press, New York.

Kim, Y.-U. and K.-H. Han. 1993. The early life history of the rockfish, Sebastes inermis. 1. Egg development and morphology of larvae by artificial treatment in aquarium. Bull. Korean Fish Soc., 26, 458-464.

Kim, Y.-U., K.-H. Han, and S.-K. Byun. 1993. The early life history of the rockfish, Sebastes inermis. 2. Morphological and skeletal development of larvae and juvenile. Bull. Korean Fish. Soc., 26, 465-476.

Kim, J.H., Y.H. Lee, Y.B. Moon, and C.S. Ko. 2001. Survival and growth of larvae and juveniles of rockfish, Sebastes inermis at different water temperature, feed and rearing density. Bull. Nat'l. Fish. Res. Dev. Inst. Korea, 59, 31-44.

Ko, C.S., Y.J. Chang, H.K. Lim, J.-H. Kim, and K.C. Cho. 1998. Controlled reproductive cycle of rockfish (Sebastes inermis) by water temperature and photoperiod. $J$. Korean Fish. Soc., 31, 713-720.

Lee, T.-Y. and S.-Y. Kim. 1992. Reproduction and embryonic development with the maternal body of ovoviviparous teleost, Sebastes inermis. Bull. Korean Fish. Soc., 25, 413-431.

Lee, J.S. and Y.D. Lee. 1996. Early gonadogenesis and sex differentiation in the viviparous teleost, Ditrema temmincki. Bull. Korean Fish. Soc., 29, 34-43.

Lee, Y.D., S. Rho, Y.J. Chang, H.J. Baek, and C.M. An. 1996. Sex differentiation of the rockfish, Sebastes schlegeli. J. Korean Fish. Soc., 29, 44-50.

Pandian, T.J. and S.G. Sheela. 1995. Hormonal induction of sex reversal in fish. Aquacuture, 138, 1-22.

Park, I.-S., H.-B. Kim, H.T. Huh, and S.C. Kim. 1993. Masculinization of masu salmon (Oncorhynchus masou) by treatment of 17á-methyltestosterone. Ocean Res., 15, 2936.

Park, I.-S., J.-H. Kim, I.-C. Bang, and D.S. Kim. 1998. Histological study of the early gonadal development and sexual differentiation in Rhynchocypris oxycephalus. Dev. Reprod., 2(1), 69-74. 
Park, I.-S., J.-H. Kim, S.H. Cho, and D.S. Kim. 2004. Sex differentiation and hormonal sex reversal in the bagrid catfish, Pseudobagrus fulvidraco (Richardson). Aquaculture, 232, 183-193.

Piferrer, F. 2001. Endocrine sex control strategies for the feminization of teleost fish. Aquaculture, 197, 229-281.

Pudey, J. and G. Callard. 1984. Identification on Leydig-like cells in the testis of the dogfish, Squalus acanthias. Anat. Res., 209, 321-330.

Romanov, A.A. and Y. Altuf'yev. 1992. Extraregional histogenesis of sexual cells in the Caspian Sea sturgeons. $J$. Ichthyol., 32, 145-154.

Romanov, A.A. and Y. Altuf'yev. 1993. Ectopic histogenesis of sexual cells of Caspian Sea sturgeons. J. Ichthyol., 33, 140-150.

Shelton, W.L. and G.L. Jensen. 1979. Production of reproductively limited grass carp for biological control of aquatic weeds. WRRI Bull. Auburn Univ., 39, 1-174.

Takahashi, H. 1977. Juvenile hermaphroditism in the zebrafish, Brachydanio rerio. Bull. Fac. Fish., Hokkaido Univ., 28, 57-65.
Takahashi, H. and M. Shimizu. 1983. Juvenile intersexuality in a cyprinid fish, the Sumatra barb, Barbus tetrazona tetrazona. Bull. Fac. Fish., Hokkaido Univ., 34, 6978

Van Vuren, J.H.J. and J.T. Soley. 1990. Some ultrastructural observations of Leydig and Sortoli cells in the testis of Tilapia rendalli following induced testicular recrudescence. J. Morphol., 206, 57-64.

Yamamoto, T. 1969. Sex differentiation. P. 117-175. In: Fish Physiology, ed. by W. Hoar and D. Randall. Academic Press.

Yamazaki, F. 1983. Sex control and manipulation in fish. Aquaculture, 33, 329-354.

Yoon, S.-J., H.-G. Hwang, K.-H. Park, S.-J. Han, Y.-H. Lee, D.-H. Kim, and J.-W. Kim. 2007. Early gonadogenesis and sex differentiation of the oblong rockfish, Sebastes oblongus. J. Aquaculture, 20, 47-50.

Received Apr. 30, 2008

Revised Jul. 15, 2008

Accepted Sep. 23, 2008 